\title{
Emerging Adulthood: Identity status and Parenting Styles
}

\author{
Justin Vianey Mercado Embalsado \\ Angeles University Foundation \\ Philippines \\ embalsado.justinvianey@auf.edu.ph
}

\begin{abstract}
The psychosocial development of emerging adults is characterized by the development of an achieved ego identity (Kroger \& Marcia, 20II). This development is influenced by the parental environment (Darling \& Steinberg, 1993). A one-way multivariate analysis was conducted to predict the associations between the different parenting styles (Baumrind, 1966) and identity statuses (Marcia, 1994). According to the results, there was a significant difference in the perceived parenting styles of the emerging adults $(N=203)$ based on their identity status, $F(8,392)=, p=$ 0.033 ; Wilk's $\Lambda=.919$, partial $\eta 2=0.4 \mathrm{l}$. To further understand the variances among the variables a discriminant analysis was conducted, which revealed that the achieved identity status led to the variances between the parenting styles and identity status. Regardless of the perceived parenting style and socialized parental attitude an achieved identity remains to be the goal of an emerging adult's identity development.
\end{abstract}

Keywords: identity status, parenting styles, emerging adulthood

Received 3 October 2021/Accepted 10 December 2021 @Author all rights reserved

\section{Introduction}

The psychosocial development of emerging adults is typically perceived through the psychosocial task of establishing an achieved ego identity (Kroger \& Marcia, 20II). Different identity statuses were conceptualized by Marcia (1966), which includes an authoritative, authoritarian, foreclosed, and identity moratorium. Darling and Steinberg (1993) suggest that identity status is associated with the family environment. Different studies reflect the cultural relativity of identity status and parenting styles (Cakir \& Aydin, 2005; Grové \& Naudé, 2016). Parenting practices are behaviors that are defined by socialization goals (Darling \& Steinberg, 1993). Parenting styles typologies were first conceptualized by Baumrind (1966), wherein three styles were identified. The first one is permissive parenting is nonpunitive, accepting, and 
affirmative to the child's behavior. Authoritarian parenting is more controlling, parents attempt to shape and control the attitudes and behavior of their children. The authoritative parenting style is more rational and issue-oriented than the previous ones. They value self-expressiveness but do not forget to restate the restrictions. In this study, it was hypothesized that parenting styles and identity status are significantly grouped. Authoritative parenting is paired with an achieved identity, authoritarian parenting with foreclosed identity, permissive parenting with diffused identity, and lastly, authoritative parenting with an identity moratorium. The study aims to predict their associations with one another by identifying the multivariate variances among the variables to prove that the hypothesis is significant.

\section{Emerging Adulthood}

Emerging adulthood is characterized by an individual's independent exploration of the different life possibilities. Late teens to mid-twenties are the most volitional years however the normative standards of culture in adult development may hinder this process. It is expected to observe an emerging adult have a subjective sense of ambiguity and instability before attaining adulthood. Accepting responsibilities and making independent decisions are character qualities in becoming self-sufficient. The majority of the youth continue to develop their identities beyond adolescence and into emerging adulthood (Arnett, 2000). The progression of identity development is present beyond adolescents towards emerging adulthood (Syed, 20I2). A better ego-identity with adolescents signifies their capacity to deal with the challenges in life (De Man, Harvey, Ward, \& Benoit, 2008).

\section{Identity Status}

The psychosocial task in ego identity development is the attainment of an achieved identity (Kroger \& Marcia, 20II). Ego identity implies that individuals can be classified into four identity statuses: identity diffusion (no exploration, no-commitment), identity moratorium (exploration, no-commitment), identity foreclosure (commitment, no exploration), or identity achievement (exploration and commitment) (Marcia, 1994). Exploration is the period of re-thinking and sorting through life plans in trying various roles. Commitment refers to the personal investment an individual expressed to a particular cause (Marcia, 1966). Achievement and foreclosure were statuses that were high in commitment, achieved status reached commitment through the 
exploratory process while foreclosure abides through authoritarian values of significant others. Identity moratorium is engaged in the exploratory period but it is struggling to attain commitments. Identity diffusion lacks commitment and it is easily influenced by external influences, they are perceived as directionless. Identity foreclosure has the highest influence from authoritarianism among the identity statuses; wherein individuals in identity foreclosure conform to the family standards to avoid family rejection (Kroger \& Marcia, 20II). Identity achievement is highest in ego identity and performs better in other statuses in a stressful task while identity diffusion is universally poorer than identity achievement (Marcia, 1966). In addition, diffused and moratorium identity statuses reflect a lack of clarity in one's identity (Ickes, Park, \& Johnson, 20I2). This reflects the diffused identity's avoidant styles and a strong sense of self-exploration with identity moratorium (Berzonsky \& Kuk, 2000). Individuals with a diffused identity do not engage with personally expressive activities (Schwartz, Mullis, Waterman, \& Dunham, 2000). It depicts their characteristics by Marcia (1994), having no sense of commitment and exploration for identity diffusion and a sole sense of exploration and crisis with identity moratorium.

Identity commitment weakens the possible crisis that identity exploration will create for individuals with achieved and foreclosed identities (Berzonsky, 2003). In terms of exploration and commitment, ruminative exploration appears to affect an individual's establishment of autonomy, sense of competence, and interpersonal relationships (Luyckx, Vansteenkiste, Goossens, \& Duriez, 2009). In the analysis of the mixed ethnic adolescent samples in the ArabEuropean population of Israel, identity achievement and moratorium express mastery and competence in managing their environment, sustaining positive relationships, and shows positive attitudes towards themselves and their lives. Foreclosure and diffusion statuses lack environmental mastery, difficulty, and frustrations in establishing positive relationships (AbbuRayya, 2006). Those who are doing well in their lives may be more willing to explore their identity and have more identity commitments (Waterman, 2000). Between the different identity statuses, Identity foreclosure has the highest influence of wherein the individual conforms to the family standards to avoid family rejection (Kroger \& Marcia, 20II). Parental attitudes are important to the psychosocial development of adolescents, the attitudes of both mothers and fathers are associated with adolescent identity formation (Sandhu, Singh, Tung \& Kundra, 20I2). 
Adolescents from authoritative families were found to be more adaptive and task-oriented while adolescents from neglectful families were most maladaptive (Aunola, Stattin, \& Nurmi, 2000).

In a longitudinal study conducted on freshmen and senior college students, Waterman, Geary, and Waterman (1974) found out that there is a significant increase of achieved identity of college students between their freshmen and senior years. Growth in occupational and ideological identity growth was observed after freshman years. Students who had an achieved identity in their freshman years had more stable identities. Unexpectedly those with foreclosed identities were occupationally stable but unstable for their ideology. Beronzky and Kuk (2000) also conducted a study on the personal identity development of university students. They found out that students that are engaged in more self-exploration have the most readiness to operate in a mature, autonomous, and self-directed manner without looking for the reassurance of others.

Those individuals with an achieved identity status also possess a positive self-image themselves. Identity achievers and moratorium rely on an informational approach, wherein they tend to use self-relevant information and are skeptical about their self-constructions. While foreclosed individuals tend to comply with the standards of their significant others.

Individuals with diffused identities tend to procrastinate, delay and avoid (Berzonsky \& Kuk, 2000). In a comparison of the four identity statuses, even though foreclosed identity does not engage in more identity exploration (Marcia, 1994). It shows to have more sense of clarity together with the achieved identity compared with the moratorium and diffused identity status (Ickes, Park, \& Johnson, 20I2). However, it still reflects the influence of authoritarianism (Kroger \& Marcia, 20I I). It is specific to the possibilities of borrowing a ready-made identity or exploring and forging one's identity through personal experience (Ickes, Park, \& Johnson, 20I2).

The progress in identity formation foreshadows the transition of students in the university (Berzonsky \& Kuk, 2000). Foreclosed identity tends to resemble the socialized attitudes of family and friends. The difference between achieved and foreclosed identity roots from the 
individual's strivings to develop their own identity than simply resembling the identity of the socializing agents such as their family and friends (Ickes, Park, \& Johnson, 20I2). The development of an achieved identity was also said to be influenced by the perception of past experiences.

A pattern of achieved vocational identity is associated with a positive perspective on the past and a diffused vocational identity perceives it negatively (Taber \& Blankemeyer, 20I5). Having a sense of self positivity is correlated with an achieved identity and negatively correlated with diffused, foreclosed, and moratorium identity statuses (Ickes, Park, \& Johnson, 2012). Achieved vocational identity is connected with the capacity to be mindful and experience pleasure in the present. It is associated with the mindful awareness of the present and to be able to enjoy the here and now. It would make sense that commitment to occupation involves the capacity to be aware, attentive, and enjoy the present without the preoccupation about the negative events (Taber \& Blankemeyer, 20I5).

The studies in identity status have not thoroughly explored the interaction of different social contexts such as school, family, and peers. In the analysis of social context, the individual's interpretation and experience must be a mediating pattern (Kroger, 2000). Excessive demands and expectations from parents in the absence of positive emotions towards their child are not indicative of identity commitments. The role of parental attitudes in adolescent psychosocial development must be explored (Sandhu, Singh, Tung \& Kundra, 20I2).

\section{Parenting Styles}

Parenting styles typologies were first conceptualized by Baumrind (1966) wherein prototypes of adult control to child-rearing practices were indicated. There were three: the first one is permissive parenting is nonpunitive, accepting, and affirmative to the child's behavior. Permissive parents allow the child to regulate their activities and do not encourage and exercise control. Authoritarian parenting is more controlling, parents attempt to shape and control the attitudes and behavior of their children. They value obedience and favors punishments to regulate the will of their child. They restrict the child's autonomy and they are the one that assigns different responsibilities without their child's own volition. Lastly, the authoritative parenting style is 
more rational and issue-oriented than the previous ones. They value self-expressiveness but do not forget to restate the restrictions. Maccoby and Martin (1983) identified two processes to Baumrind's (1966) parenting styles.

They also identified a fourth parenting style in addition to the three parenting styles. The two processes state that parenting styles are best understood from the number of demands enforced by the parents and the parental reinforcements or responsiveness to the developmental needs of their child. They stated that authoritative parents are high in both demandingness and responsiveness, authoritarian parents are high in demandingness but low in responsiveness, permissive parents are low in demandingness but high in responsiveness, and lastly, this addition was derived from the permissive parenting style, they stated that neglectful parenting style is both low in responsiveness and demandingness. Hence, the conceptualization of Baumrind (1966) and Maccoby and Martin (1983) gives a complex dimension to parenting styles, with four of them and two specific parenting processes. In this present study, the association of identity status and parenting styles will be explored. Each parenting attribute influences the child's development (Darling \& Steinberg, 1993). Marcia (1966) a proponent of the empirical analysis of the identity statuses stated that there is an association with the development of identity with the parenting styles.

\section{Parenting Styles and Identity Status}

Even before the publication of the identity status (Marcia, 1966) and parenting styles (Baumrind, 1966), studies about the association of identity status and parenting styles were conducted. Becker (1964) suggested that individuals with permissive, neglecting, or rejecting parents are more likely to have a diffused identity status, while those with authoritarian parents can be foreclosed on parental choices. Democratic parenting styles are more conducive for different identity alternatives and form an achieved identity. However, a foreclosure can be expected to an adolescent for early decisions receiving parental support. Individuals in identity foreclosure have the closest relationship with their parents. Those with identity diffusion are contrary; they are reported to be the most distant to their family. Their parents were seen as indifferent, inactive, detached, not understanding, and rejecting. Individuals in the moratorium identity status reported conflicting with their families. Males do not consult their families to their 
decisions. A better resolution to the identity crisis can lead to the improvement of the family relationship (Wateman, 1982). As mentioned earlier, foreclosed identity is inclined with abiding by authoritarian values (Kroger \& Marcia, 20II; Ryeng, Kroger, \& Martinussem, 20I3), an individual conforms to the family values to avoid rejection.

A study by Aunola, Stattin, and Nurmi (2000) that analyzed parenting styles and adolescent achievement revealed that. Adolescents from authoritative families have the most adaptive achievement strategies. Adolescents from neglectful families apply maladaptive strategies, characterized by passivity and lack of self-enhancement attributions. Authoritative families were high in responsiveness and child-centeredness but also high in demandingness while neglectful families were neither controlling nor responsive. Permissive families were characterized by low parental control but more child-centered than neglectful families. Authoritarian families have high levels of parental control and low parental trust. Family relations that are characterized by poor involvement, lack of parental trust, engagement, and control, seem to use maladaptive achievement strategies. School achievement communicates a child's socialization towards adulthood, these reflect the impact of family parenting styles on long-term consequences. Hence, parenting styles are important in the development of achievement strategies. In support Spera (2005) reviewed the relationship between parenting styles and school achievement, the findings were.

Authoritative parenting styles are associated with higher levels of student achievement. However, a decline in parental involvement was observed, this is to allow the child's need to express their autonomy. Even away from home, college student's academic performance is still influenced by their parents, especially those with authoritative parenting styles. Characteristics such as supportiveness and warmth have important roles in academic performance even until college. Permissive and authoritarian parenting styles do not significantly predict academic performance. Parental influence is important in young adult's academic performance. It keeps its influence throughout this transition stage even away from home (Turner, Chandler, \& Heffler, 2009). Different parenting styles will reflect different pathways in identity formation (Becker, 1964). 
The psycho-social development of adolescence is influenced by parenting (Schucksmith, Hendry, \& Glendinning, 1995). Parenting practices are behaviors defined by socialization goals. Parenting style is a collection of attitudes that are communicated to the child wherein the parental behaviors are expressed (Darling \& Steinberg, 1993). A study conducted in Turkey about parental attitudes and identity status in the adolescent population had different results from Becker's (1964) assumptions. According to this study, authoritative parenting styles lead to the development of identity foreclosure in their children. Turkish parents foster acceptance and control, dependence by restricting their autonomy and self-direction. Parental attitudes of Turkish parents can be considered as culturally modified attitudes of authoritative parenting. (Cakir \& Aydin, 2005). A study in South Africa also claims that parenting styles that promote specific identity status vary between collectivistic and individualistic cultures. Its results state that permissive parenting style predicts the achieved identity status, while authoritative parenting style predicts diffused identity status. In a collectivistic culture, exploration of individuality is not encouraged, and adhering to the collective identity is favored (Grové \& Naudé, 2016). As a result, different culture concludes with different patterns of identity status and parenting styles. It can be stated that parenting styles are thought of as a contextual variable (Darling \& Steinberg, 1993).

In context, a study that compared the identity status of undergraduate students of Egypt and Kuwait, the researcher found out that Egyptians were more achieved, less foreclosed, and less diffused compared to the Kuwait samples but there were no significant differences in identity moratorium. These results were accounted for the Egyptian adult's attitude in finding jobs that can provide economic and social stability. They spend a period of exploration before they land to solid commitments. They achieve more than the Kuwaitis because they spend more time exploring better goals than giving little effort to attain simple wishes. This context also explains the Egyptian sample's less foreclosed and less diffused identities (Megreya \& Ahmed, 201I). A comparison between different nations in Europe was conducted in Swedish, Greek, and Italian samples, Greek parents were $\mathrm{P}$

Perceived as less authoritarian and more permissive than Italian parents; Swedish parents were less authoritarian than Italian and Greek parents are more permissive than Italian parents 
(Olivari, Wahnb, Maridaki-Kassotakic, Antonopoulouc, \& Confalonieria, 20I5). Italian emerging adults perceived their parents as agents of identity development who are responsive and supportive of autonomy. They encourage the young people's active involvement in their identity formation. As their child grows older, they expect them to be more committed and involved within their family (Sestito, \& Sica, 2014).

Comparing samples between collectivist and individualist cultures was portrayed through the comparison between Indian and American college students. Indian college students perceived that permissive parenting is more effective and helpful while American college students considered authoritative and authoritarian parents to be more effective, helpful, and caring. However, both Indian and American college students opt to have a parent that demonstrates authoritative parenting. The perspective of Indian college students is influenced by the traditional Indian parenting styles and the changes in their society brought by globalization. It must be noted that the American and Indian samples belonged to the upper-middle-class socioeconomic status (Barnhart, Raval, Jansari, \& Raval, 2013). In China, an individual's autonomy is found to be negatively associated with their parent's perceived authoritative parenting style and school achievement (McBride-Chang \& Chang, 1998).

Children in collectivist cultures perceive authoritarian parenting with parental rejection, hostility, and disconnection. Permissive and authoritarian parents do not show reciprocity by failing to understand the perspective of their child (Sorkhabi, 2012). Adolescents who perceive their parents as authoritative were found to demonstrate better academic pursuits (Rivers, Mullis, Fortner, \& Mullis, 20I2). The different evidence on the variances between identity status and parenting styles reflects the importance of considering the cultural context in understanding parenting (Rodriguez, Donovick, \& Crowley, 2009).

Psychosocial development of emerging adults, known for ego development, which was operationalized through research by the Identity status of Marcia (1966) is suggested to be associated with family environment (Darling \& Steinberg, 1993). The studies between identity status and parenting styles have shown to be relative to each culture and developmental stages (Cakir \& Aydin, 2005; Grové \& Naudé, 2016). This reflects the need to analyze these variables 
in several contexts to obtain a better understanding of their relationship. The analysis aims to have a contextual understanding of the emerging adult's psychosocial development.

\section{Present Study}

The current study explored if specific parenting styles will lead to different identity statuses of merging adults. Four hypotheses were developed for this contention with I) Individuals who perceive their parents with an authoritative parenting style are more likely to develop achieved identity, 2) Individuals who perceive their parents with an authoritarian parenting style are more likely to develop foreclosed identity, 3) Individuals who perceive their parents with authoritative parenting styles are more likely to develop identity moratorium, 4) Individuals who perceive their parents with a permissive parenting style are more likely to develop identity diffusion.

Hypothesis I: Individuals who perceive their parents with an authoritative parenting style are more likely to score high in identity achievement compared with the authoritarian and permissive parenting styles. The goal of ego development is to attain an achieved identity (Arnett, 2000), parents play a role in supporting and encouraging their child to get involved in the process of exploration (Rivers, Mullis, Fortner, \& Mullis, 2012; Sestito, \& Sica, 20I4). There are differences among cultures but they still prefer authoritative parenting even though there were variances in their values regarding personal growth and autonomy (Megreya \& Ahmed, 20II; Barnhart, Raval, Jansari, \& Raval, 20I3). Collectivist culture prefers a family that is more adaptive and provides the emotional support that an individual needs to attain an achieved identity (Sorkhabi, 20I2). Individuals from authoritative families show to be more adaptive to stress (Aunola, Stattin, \& Nurmi, 2000).

Hypothesis 2: Individuals who perceive their parents with an authoritarian parenting style are more likely to score high in foreclosed identity compared with authoritative and permissive parenting. Individuals with foreclosed identity practice the socialized behavior from their parents to an experience of rejection and authoritarian parents expects the obedience of their child, without the appreciation to the individual's autonomy and own self-exploration (Ickes, Park, \& Johnson, 20 I2; Kroger \& Marcia, 20 I ; Maccoby \& Martin, 1983). 
A foreclosed identity is characterized by an identity commitment even without an identity exploration. Hence even without reconsiderations of life roles, there is already a provided personal investment to a particular cause (Marcia, 1966, 1994). This leads to individuals in a foreclosed identity lacking environmental mastery, difficulty, and frustrations in establishing positive relationships (Abbu-Rayya, 2006). They tend to borrow ready-made identities and miss out on identity development through personal experiences (Ickes, Park, \& Johnson, 2012). They also conform to family standards to avoid family rejection (Kroger \& Marcia, 20I I). It directly reflects the socialized attitudes from the family, simply resembling the identity of the socializing agents (Ickes, Park, \& Johnson, 20I2). Foreclosed identity has been tied with authoritarianism (Kroger \& Marcia, 20II). Authoritarian parenting is more controlling and values obedience and punishment to regulate the child's behavior (Baumrind, 1966). This is a kind of family relationship that is characterized by poor involvement, lack of parental trust, engagement, and control; seems to use maladaptive achievement strategies (Aunola, Stattin, \& Nurmi, 2000). This portrays the character of authoritarian parenting as high in demandingness but low in responsiveness (Maccoby \& Martin, 1983). Authoritarian parents do not show reciprocity by failing to understand the perspective of their child and disregards the autonomy (Sorkhabi, 2012; Baumring, 1966). Nonetheless, foreclosed identity is inclined with abiding by authoritarian values as observed from the strong influence of their parents (Kroger \& Marcia, 20II; Ryeng, Kroger, \& Martinussem, 2013).

Hypothesis 3: Individuals who perceive their parents with authoritative parenting styles are more likely to score high in identity moratorium compared with the authoritarian and permissive parenting styles. Identity moratorium is characterized by an exploration without any commitment within an identity (Marcia, 1994). It is the status wherein reconsiderations on the different life plans are done and trying new roles are emphasized (Marcia, 1966). Those college students who are engaged in self-exploration are more ready to operate in a more mature, autonomous, and selfdirected manner (Berzonsky \& Kuk, 2000). However, ruminative exploration affects an individual's autonomy, sense of competence, and interpersonal relationships (Luyckx, Vansteenkiste, Goossens, \& Duriez, 2009). Both achieved and moratorium identity status expresses mastery and competence in managing their environment, sustaining positive 
relationships, and shows positive attitudes towards themselves and their lives. (Abbu-Rayya, 2006). Identity exploration can lead an individual to land a relevant personal investment Megreya \& Ahmed, 20II). This development of autonomy can be done through receiving support from parents. Italian emerging adults perceived their parents as agents of identity development who are responsive and supportive of autonomy. They encourage the young people's active involvement in their identity formation. As their child grows older they expect them to be more committed and involved within their family (Sestito, \& Sica, 20I4). This integration of identity status and parenting reflects the essence of a parenting style that is more rational and issue-oriented, that values self-expressiveness but does not forget to restate the restrictions (Baumrind, 1966).

Hypothesis 4: Individuals who perceive their parents with a permissive parenting style are more likely to score high in identity diffusion compared with the other authoritarian and authoritative parenting styles. Identity diffusion is the identity status that does not have exploration and commitment (Marcia, 1994). They are not engaged in personally expressive activities (Schwartz, Mullis, Waterman, \& Dunham, 2000). It is the identity status that is most distant to their family. Their parents were seen as inactive and detached Becker (1964). Permissive parents are undemanding but show responsiveness. There is no parental control and a little amount of attention is given. This kind of parenting applies maladaptive strategies, characterized by passivity and lack of selfenhancement attributions (Aunola, Stattin, \& Nurmi, 2000). An emerging adult in this point will not achieve self-enhancement and self-involvement to identity exploration due to the socialized attitudes of their parents (Rivers, Mullis, Fortner, \& Mullis, 20I2; Sestito, \& Sica, 20I4). This will lead to an identity status without exploration and commitment.

\section{Method}

\section{Design}

A predictive cross-sectional research design will be used for this study. The researcher intends

to predict interactions between the different parenting styles and identity statuses. It is the objective of the study to identify the patterns of specific parenting styles and identity statuses that will best characterize the emerging adult's development within a contextual perspective. All 
of the data for each of the research participants will be collected at a single point in time (Johnson, 200I).

\section{Participants}

Recruitment and participation in the study are voluntary. Participants can discontinue at any point of the data gathering. An informed consent which, describes the purpose, procedures, risks, benefits, confidentiality and data management of the study was provided. The identity of the participants will remain anonymous, and any personal information that can identify the participant from the research will not be presented. The data was stored in a secured drive of the researcher which will be kept for 5 years.

203 individuals participated in this study. Their age ranged from 18 to 25 , following the criteria of emerging adulthood $(M=20.14$ years, $S D=1.86)$. There were $87(43.1 \%)$ female participants and II5 (56.9\%) male participants. To qualify as research participants two criteria were given. I.) The participants in this study are 18 to 25 years of age individuals, who are categorized as emerging adults (Arnett, 2000). 2.) 2. They are single at the time of data gathering. Married individuals encounter a developmental transition wherein their period of exploration may differ from unmarried emerging adults (Arnett, 2000).

\section{Sampling}

Purposive sampling was used for this study to assure that all participants are emerging adults. Before an individual will qualify as a research participant the age and marital criteria must be met. Purposive sampling is made by the researcher to select participants who are most representative in the research (Coolican, 2014).

\section{Instruments}

The revised version of the Extended Objective Measure of Ego-Identity Status -II (EOM-EIS -II; Bennion \& Adams, 1986) was used to measure the identity status of emerging adults. This test aims to identify the identity status of an individual. The structure of Marcia's (1966) identity statuses was followed. The 64-item scale follows a 6-point Likert scale format. The four statuses of this scale (diffusion, achievement, foreclosure, and moratorium) have 16-items each. 
An example for each is as follows: achievement "After a lot of self-examination I have established a very definite view on what my lifestyle will be."); diffusion ("I'm not interested in finding the right job; any job will do. I just seem to flow with what is available."); foreclosure ("I attend the same church my family has always attended. I've never really questioned why."); moratorium ("I don't know what kind of friend is best for me. I'm trying to figure out exactly what friendship means to me."). In the original scale of Benion \& Adams (1986) the EOM-EIS II obtained a Cronbach alpha that ranges from .60 to .80 . A current study by Ghassemi (2017) reflects the reliability of the scale, obtaining a Cronbach alpha that ranges from 0.60 to 0.88 . The scale obtained an interim full-scale Cronbach Alpha of 0.873 .

The Parental Authority Questionnaire (Buri, 199I) will be used to measure Baumrind's (1966) three parenting styles: authoritative, authoritarian, and permissive. The questionnaire followed Baumrind's structure of the parenting styles, a 30-item; 5-point Likert format will be used. Each factor in the questionnaire has 10 items each. Items are structured as follows: authoritative ( "As I was growing up, once the family policy had been established, my mother discussed the reasoning behind the policy with the children in the family." ), authoritarian ("Even if her children didn't agree with her, my mother felt that it was for our good if we were forced to conform to what she thought was right." ), and permissive ("While I was growing up my mother felt that in a well-run home the children should have their way in the family as often as the parents do." ). Buri (1991) reported good internal consistency coefficients ranging between 74 and .87 and two-week test-retest reliability coefficients ranging between .77 and .92. The PAQ obtained an interim full-scale Cronbach Alpha of 0.79 which indicates a high level of internal consistency.

\section{Procedures}

Participants were selected through the given criteria. Survey forms were conducted to senior high school, college, and graduate school students. The participants were initially asked if they are willing to participate in research about identity development and if they are aged between 18 and 25 and not currently married to identify if they fall to the criteria of being an emerging adult. The research questionnaires and informed consent were distributed, and then the nature of the study was discussed. They filled the personal information section which includes their sex 
and age. This procedure was then followed by the completion of the research questionnaires to measure the concerned variables. An online survey was also conducted which was distributed across the web through google.

\section{Results}

A Pearson $r$ correlation was conducted to learn more about the relationship among the dependent variables to identify the possibility of any multicollinearity in the preliminary phase of analysis. In the One-way Multivariate Analysis of Variance (MANOVA), the parenting styles will serve as the independent variable that is consisted of three categories and the four identity statuses will be the dependent variables. In the analysis, the variances of means between the different identity statuses within categories of the parenting styles will be compared to one another to determine which pattern of parenting styles and identity status will be matched together. Hence a pattern between the identity status and parenting styles will be identified.

The one-way MANOVA was conducted with the multivariate analysis, test between the independent and dependent variables, and a post hoc analysis for those groupings that are statistically significant on the test between the independent and dependent variables. In identifying the specific categories for each of the participant's perceived parenting styles the suggestion of Smetana (1995) was followed. Where the highest mean between the three categories will be used?

Table I

Pearson Product-Moment Intercorrelations Among Dependent Variables

\begin{tabular}{lllll}
\hline Variable & I & 2 & 3 & 4 \\
\hline I. Achieved & - & & & \\
2. Foreclosed & $.157^{*}$ & - & & \\
3. Moratorium & $.413^{* * *}$ & $.444^{* * *}$ & - & - \\
4. Diffused & $.161^{*}$ & $.348^{* * *}$ & $.587^{* * *}$ & \\
\hline
\end{tabular}

$*_{p}<.05 .{ }^{*} \mathrm{p}<.001 .{ }^{* * *} \mathrm{p}<.0001$. 
Table I shows the intercorrelations among the dependent variables used in the study. The objective measure of ego identity was analyzed. The Pearson $r$ correlation coefficients of the identity status range from a weak to a moderate relationship. This reflects the absence of multicollinearity among the variables. Tabachnick and Fidell (20I2) recommend that the dependent variables must be negatively correlated or have a moderate relationship to avoid multicollinearity.

Table 2

Descriptive Statistics for Identity status and Parenting style

\begin{tabular}{lllll}
\hline Identity Status & Parenting Style & Mean & SD & N \\
\hline Achieved & Authoritarian & 53.346 & 6.5825 & 52 \\
& Authoritative & 55.673 & 6.2898 & 101 \\
& Permissive & 53.306 & 7.3519 & 49 \\
& Total & 54.500 & 6.7058 & 202 \\
\hline Foreclosed & Authoritarian & 45.404 & 8.8212 & 52 \\
& Authoritative & 43.990 & 7.7117 & 101 \\
& Permissive & 47.041 & 8.6770 & 49 \\
& Total & 45.094 & 8.2989 & 202 \\
\hline Moratorium & Authoritarian & 50.558 & 7.2556 & 52 \\
& Authoritative & 49.406 & 7.1249 & 101 \\
& Permissive & 50.531 & 7.2603 & 49 \\
& Total & 49.975 & 7.1782 & 202 \\
\hline Diffused & Authoritarian & 48.538 & 8.6034 & 52 \\
& Authoritative & 46.782 & 7.3873 & 101 \\
& Permissive & 49.245 & 7.3386 & 49 \\
& Total & 47.832 & 7.7435 & 202 \\
& & &
\end{tabular}

Note: $\mathrm{N}=202$

Table 2 shows the descriptive statistics for the variables in the different categories of parenting styles and identity status. A MANOVA was conducted to determine the relationship between parenting styles and identity status. Achieved identity obtained its highest mean based on the Authoritative parenting style $(M=55.67, S D=6.29)$, Foreclosed identity from Permissive 
parenting style $(M=47.04, S D=8.68)$, Identity Moratorium on Authoritarian parenting styles $(M=50.56, S D=7.25)$, and Diffused identity on Permissive parenting Style $(M=49.83, S D=$ 7.33).

Table 3

MANOVA results

\begin{tabular}{|c|c|c|c|c|c|c|}
\hline \multirow[t]{2}{*}{ Effect } & \multirow[t]{2}{*}{ Test Statistic } & \multirow[t]{2}{*}{ Value } & \multirow[t]{2}{*}{$F$} & \multirow[t]{2}{*}{ df } & \multirow{2}{*}{$\begin{array}{l}\text { Partial } \\
\mathrm{n}^{2}\end{array}$} & \multirow{2}{*}{$\begin{array}{l}\text { Noncentrality } \\
\text { Parameter }\end{array}$} \\
\hline & & & & & & \\
\hline \multirow[t]{5}{*}{ Intercept } & Pillai's Trace & .989 & 4347.39 |**** & 4,196 & .989 & 17389.566 \\
\hline & Wilks' Lambda & .011 & $\left.4347.39\right|^{* * *}$ & 4,196 & .989 & 17389.566 \\
\hline & Hotelling's Trace & 88.722 & $4347.391^{* * * *}$ & 4,196 & .989 & 17389.566 \\
\hline & Largest & 88.722 & $4347.391 * * *$ & 4, 196 & .989 & 17389.566 \\
\hline & Root & & & & & \\
\hline Parenting & Pillai's Trace & .082 & $2.097^{*}$ & 8,394 & .041 & 16.779 \\
\hline \multirow[t]{4}{*}{ Style } & Wilks' Lambda & .919 & $2.12 \mathrm{lb}^{*}$ & 8,392 & .041 & 16.970 \\
\hline & Hotelling's Trace & .088 & $2.145 *$ & 8,390 & .042 & 17.160 \\
\hline & Largest & .082 & $4.059 *$ & 4, 197 & .076 & 16.235 \\
\hline & Root & & & & & \\
\hline
\end{tabular}

Note: $\mathrm{N}=202, \mathrm{p}<.05 *, \mathrm{p}<.01^{* *}, \mathrm{p}<\left..00\right|^{* * * *}$

There is a significant difference in the parenting styles of emerging adults based from their identity status, $F(8,392), p=0.033$; Wilk's $\Lambda=.919$, partial $\eta 2=0.41$. Wilk's Lambda was used as the basis for its statistical analysis because of its statistical capacity to directly measure the proportion of variance with groupings of dependent and independent variables. If a large proportion of variance is accounted for by the independent variable, it will suggest the effect in the grouping variable (Everitt \& Dunn, 1991). 
Table 4

Comparisons Between Parenting Styles and Identity Status (MANOVA)

\begin{tabular}{lllll}
\hline Source & $\begin{array}{l}\text { Dependent } \\
\text { Variables }\end{array}$ & $\mathrm{df}$ & $F$ & Partial $\mathrm{n}^{2}$ \\
\hline Parenting Style & Achieved & 2,199 & $3.159 *$ & .031 \\
& Foreclosed & 2,199 & 2.308 & .023 \\
& Moratorium & 2,199 & .633 & .006 \\
& Diffused & 2,199 & 1.979 & .020 \\
\hline
\end{tabular}

Note: $\mathrm{N}=202, \mathrm{p}<.05 *, \mathrm{p}<.01 * *, \mathrm{p}<.001 * * *$

In test of the test of between-subject effects, parenting styles have no significant effect on any identity status. Achieved Identity $(F(2,192)=3.159 ; p=.045 ;$ partial $\eta 2=.03 \mathrm{I})$, Foreclosed $(F$ $(2,192)=2.308 ; p=.102 ;$ partial $\eta 2=.023)$, Moratorium $(F(2,192)=.633 ; p=.532$; partial $\eta 2=.006)$, and Diffused identity $(F(2,192)=1.98 ; p=.141 ;$ partial $\eta 2=.020)$.. Hence a post hoc analysis on the differences among its means based on the different parenting styles will not be conducted.

As recommended by Field (2009) the MANOVA can be followed up with discriminant analysis to understand the variances among the variables. The analysis revealed two discriminant functions. The first explained $93 \%$ of the variance, canonical R2 $=.28$, whereas the second explained only $6.4 \%$, canonical $\mathrm{R} 2=.07$. The parenting styles significantly grouped with the different identity status, $\Lambda=0.92, \chi 2(8)=16.74, p=0.033$, but removing the first function indicated that the second function did not significantly differentiate the parenting styles, $\Lambda=$ 1.00, $\chi 2(3)=1.10, p=0.78$. The correlations between outcomes and the discriminant functions revealed that achieved identity does not show an even loading on both functions $(r=-0.6 / 4$ for the first function and $r=0.337$ for the second). Diffused identity had a higher loading for the first function $(r=0.490)$ compared to the second $(r=0.150)$. Identity moratorium followed the trend having the first function $(r=0.274)$ being higher than the second $(r=-0.181)$. The foreclosed identity had its first function $(r=0.502)$ to be lower than the second $(r=0.658)$. The discriminant analysis indicates that a particular univariate association between parenting 
style and identity status exist which leads to the statistical significance of the multivariate analysis. The variance in the first function of the given correlations of the outcomes and the discriminant functions reflects the inequality on the variances among the four identity statuses. It seems that achieved identity $(r=-0.614)$ has the highest correlation with the other variables, also noting its inverse relationship with the other identity status.

\section{Discussion}

The present study intends to learn the specific groupings between parenting styles and identity status. It was hypothesized that authoritative parenting is significantly grouped with an achieved identity, authoritarian parenting with a foreclosed identity, permissive parenting with a diffused identity, and lastly authoritative parenting with an identity moratorium. The perceived parenting styles of the research participants were identified and analyzed with the achieved, foreclosed, diffused, and identity moratorium statuses. The construction of the hypotheses was drawn from the context of emerging adulthood (Arnett, 2000) which intends to look through parenting styles (Baumrind, 1994) and identity status (Marcia, 1966). It also relies on cultural explanations regarding their associations. An adoptive family in a collectivistic culture is the kind that provides emotional support that guides an individual to attain an achieved identity (Sorkhabi, 20I2). Parenting practices are defined by socialization goals; parenting style is a collection of attitudes that are communicated with parental behaviors (Darling \& Steinberg, 1993).

A MANOVA was conducted to prove the hypothesis. The multivariate analysis was significant and the independent and dependent variables yielded did not yield any significant result between parenting styles and identity status. A discriminant analysis was conducted to understand the variances among the identity status based on the parenting styles. The hypothesis on the groupings between authoritarian parenting and foreclosed identity, permissive parenting and diffused identity, and authoritative parenting with identity moratorium was found to be not significant.

It was hypothesized that an authoritative parenting style will lead to the development of an authoritative identity for emerging adults. Italian emerging adults perceived their parents as 
agents of identity development who are responsive and supportive to their autonomy; through their encouragement to active involvement in their identity formation (Sestito, \& Sica, 20l4). However, the study found out that an achieved identity is not significantly grouped with authoritative parenting. The study obtained a different result from the assumption of Becker (1964) which paired authoritative parenting and achieved identity. In a study conducted in Turkey, authoritative parenting styles lead to the development of foreclosed identity. Turkish parents foster acceptance and control, dependence by restricting their autonomy and selfdirection (Cakir \& Aydin, 2005). In South Africa, permissive parenting styles predict the formation of achieved identity status (Grové \& Naudé, 2016). Different culture concludes with different patterns between parenting styles and identity status. This reflects the variance between the western conceptualization of Becker (1964) with eastern cultures. This further reflects that collective culture does not encourage identity exploration and promotes adherence to cultural values (Grové \& Naudé, 2016). It reiterates that different culture concludes with different patterns of identity status and parenting styles (Darling \& Steinberg, 1993).

Foreclosed identity is not significantly grouped with authoritarian parenting. In the typical conceptualization of identity, foreclosure is about conforming to the family standards to avoid family rejection (Kroger \& Marcia, 20II). It emphasizes the development of an ego identity by resembling the socialized attitudes of their family and friends (Ickes, Park, \& Johnson, 20I2). Basically, authoritarian parents are known to be controlling (Baumrind, 1966). However, literature from Pakistan states that excessive demands and expectations from parents are not indicative of an identity commitment (Sandhu, Singh, Tung \& Kundra, 2012). Even though foreclosed identity tends to form a strong sense of identity commitment without a crisis; it also adds up that the development of a poor identity commitment is a characteristic of a diffused identity (Marcia, 1994). The high levels of parental control are indicative of poor involvement, lack of parental trust, and engagement (Aunola, Stattin, \& Nurmi, 2000). The lack of involvement, trust, and engagement is par with the description of permissive parenting, having a low level of involvement (Baumrind, 1966). In Turkey, a foreclosed identity is developed through authoritative parenting relies on the given parental support (Cakir \& Aydin, 2005). It seems that a collective culture's preference to parenting and influence to identity development 
The current conceptualization and various cultural evidence reflects the different beliefs of each era and culture to the development of a foreclosed identity and the influence of an authoritarian parenting style to the ego development of an individual. Recent findings portray that the pairing of a foreclosed identity and authoritarian parenting may vary in a different cultural environment, even though they are conceptually linked across the theory of Baumrind (1966) and Marcia (1994).

Authoritative parenting does not lead to the development of an identity moratorium. Authoritative parenting is considered as rational democratic parenting where it shows both demands and response that caters to the development of an individual (Maccoby \& Martin, 1983). In Egypt, individuals who experience more self-exploration tend to obtain an achieved identity (Megreya \& Ahmed, 20l I). However ruminative exploration affects the development of autonomy, sense of competence, and interpersonal relationships (Luyckx, Vansteenkiste, (Goossens, \& Duriez, 2009). This leads to the development of the moratorium, having no commitment and a high level of crisis, pertaining to a period of exploration (Marcia, 1994). However, parents in collectivistic cultures favor the adherence to collective identity and discourage the exploration of individuality (Grové \& Naudé, 2016). Collective culture prefers parental support to attain an achieved identity (Sorkhabi, 20I2). This complements Waterman's (1982) findings that individuals in an identity moratorium are in conflict with their families. The expression of an identity moratorium and phase of self-exploration is cultivated without any sense of commitment (Marcia, 1994). In Italy, parents are perceived as agents of identity development who are responsive and supportive of autonomy. They encourage the young people's active involvement in their identity formation. However, as they grow older they are expected to be more committed to their family (Sestito, \& Sica, 20I4). Turkish parents foster acceptance and control, dependence by restricting their autonomy and self-direction. Parental attitudes of Turkish parents can be considered as culturally modified attitudes of authoritative parenting. (Cakir \& Aydin, 2005). The standard of collectivist culture to conform to cultural identity neglects the phase of moratorium (Sorkhabi, 2012).

The literature reflects the various perception of culture to parental environment towards selfexploration. Self-exploration is not observed in all cultures. However, it can be observed if 
there are no expectations and control from their parents. This leads to personal autonomy and engagement in identity development. This environment depicts a permissive parenting the shows little regard and no expectations (Baumrind, 1966). A decline of parental involvement allows self-exploration and expression of autonomy (Turner, Chandler, \& Heffler, 2009). Parents that will allow their offspring for self-exploration will lead to the development of a moratorium however self-exploration in different cultures is treated differently. Collectivist cultures will only tolerate a cultural identity unless the parenting style is nonresponsive and undemanding.

Permissive parenting is not a significant predictor in developing a diffused identity. In South Africa, permissive parenting predicts an achieved identity status while authoritative parenting predicts a diffused identity (Grové \& Naudé, 2016). Indian college students perceived permissive parenting to be more helpful in their schooling. The perspective of Indian college students is influenced by the traditional Indian parenting styles and the changes in their society brought by globalization (Barnhart, Raval, Jansari, \& Raval, 20I3). Cultures that expect a collective identity impose their values without regard for autonomy (Sorkhabi, 2012). As a result the conceptual depiction of permissive parents being unresponsive and undemanding (Maccoby \& Martin, 1983). A diffused identity as an associated variable is not consonant with cultural considerations. Where deviating from the cultural identity contributes to self-direction and self-exploration. Hence, permissive parenting does not predict diffused identity in this context.

Parenting styles significantly contribute to the development of an individual's identity status. The significance of the association of parenting styles and identity status is accounted to the achieved identity status, where it loaded the highest correlational value with the other identity status on the discriminant analysis. The canonical correlation in the discriminant analysis reflects the impact of the variable on the variances within the analysis. Given these findings, it still does not support the hypothesized groupings in the study. It shows that an achieved identity can be observed in any kind of parenting style. It seems that an emerging adults will attain an achieved identity regardless of the parenting they may encounter. Ego identity development aims to attain an achieved identity (Kroger \& Marcia, 20II). Individuals with an achieved identity strive 
to attain their own sense of ego development (Ickes, Park, \& Johnson, 20I2). Across cultures, it appears that different kinds of parenting styles lead to the development of achieved identity. Italian emerging adults perceived their parents as agents of identity development who are responsive and supportive to their autonomy; through their encouragement to active involvement in their identity formation (Sestito, \& Sica, 2014).

Emerging adults will strive to obtain an achieved identity regardless of their experiences with the parenting they have experienced. It meets the goal of ego development to attain an achieved identity (Kroger \& Marcia, 201I). As an individual becomes older and becomes closer to adulthood, they are expected to accept responsibilities and make independent decisions are character qualities in becoming self-sufficient (Arnett, 2000). In Egypt, individuals establish their achieved identity through taking a journey of exploration (Megreya \& Ahmed, 20ll). Exploration tackles an individual's independence to encounter different life possibilities (Arnett, 2000). Those who are engaged in self-exploration will be ready for a mature, autonomous, and self-directed identity (Beronzky \& Kuk, 2000). The development of an achieved identity is the goal of each emerging adult regardless of the response and demand that they receive from their parents.

Emerging adult's identity development is influenced by the socialized values of the parental environment. Parenting styles and identity statuses are significantly grouped together. The perceived parenting styles of emerging adults to their parental environment predict the development of their ego-identity. The significance between the variance in the identity status based on parenting styles is accounted for the achieved identity. Regardless of the parenting style, an emerging adult will emerge to fulfill the characteristics of an achieved ego-identity.

\section{Limitations and Future Directions}

In conducting a further analysis about parenting styles and identity status the adherence to cultural values and level of socialization of parents can be considered as possible mediating or moderating variables. In the analysis of social context, the individual's interpretation and experience must be a mediating pattern (Kroger, 2000). The different evidence on the variances 
between identity status and parenting styles reflects the importance of considering the cultural context in understanding parenting (Rodriguez, Donovick, \& Crowley, 2009).

The progress and dimensions of identity development can also be included with the different identity statuses, such as the vocational and ideational dimensions of the identity status. The educational and socio-economic status of the research samples must also be considered having a more contextual approach on looking through this particular aspect of an emerging adult's development. It must be noted that the parenting styles were identified by the respondents themselves, possible biases regarding their desired parenting styles from their parents can be observed; learning that collectivistic culture prefers a family that is more adaptive (Sorkhabi, $2012)$.

\section{References}

Aunola, K., \& Nurmi, J-E. (2005). The role of parenting styles in children's problem behavior. Child Development, 76 (6), II44-I I59.

Aunola, K., Stattin, H., \& Nurmi, J-E. (2000). Parenting styles and adolescents' achievement strategies. Journal of Adolescence, 23, 205 - 222. doi: 10.1006/jado.2000.0308.

Baker. A.J.L., \& Verrocchio, M.C. (2013) Italian college student- reported childhood exposure to parental alienation: correlates with well-being. Journal of Divorce \& Remarriage, 54 (8), 609-628. doi: 10.1080/10502556.2013.8377/4.

Barnhart, C.M., Raval, V.V., Jansari, A., \& Raval, P. (2013). Perceptions of parenting style among college students in India and the United States. Journal of Children and Family Studies, 22, 684-693. doi:I0.1007/s 10826-0I2-962I-I.

Barber, B. K. (1996). Parental psychological control: Revisiting a neglected construct. Child Development, 67, 3296-3319.

Bayani, A. A., Koocheky, A. M., \& Bayani, A. (2008). Reliability and validity of Ryff's psychological well-being scales. Iranian Journal of Psychiatry and Clinical Psychology, I4, I46-I5I.

Becker, W. C. (1964). Consequences of different kinds of parental discipline. In M. L. Hoffman \& L. W. Hoffman (Eds.), Review of child development research. New York: Russell Sage Foundation. 
Bennion, L. D., \& Adams, G. R. (1986). A revision of the Extended Version of the Objective Measure of Ego-identity Status: An identity instrument for use with late adolescents. Journal of Adolescent Research, I, 183-198.

Benson, J. E., \& Johnson, M. K. (2009). Adolescent family context and adult identity formation. Journal of Family Issues, 30(9), I265-I286. doi:I0.1 I 77/0 I925I3X093.32967.

Berzonsky, M.D. (2003). Identity style and well-being: does commitment Matter. Identity, 3 (2), |3|-|42, doi: |0.1207/s|532706xid030203.

Berzonsky, M.D., \& Kuk, L.S. (2000). Identity status, identity processing style, and the transition to university. Journal of Adolescent Research, 15(I),8I-98. doi: I0.1I77/0743558400I51005.

Brown, L., \& lyengar, S. (2008) Parenting styles: the impact on student achievement. Marriage \& Family Review, 43(I-2), I4-38. doi: I0.1080/01494920802010I40.

Buri, J.R. (199I). Parental authority questionnaire, Journal of Personality Assessment, 57(I), I I0II9. doi: I0.I207/sI5327752jpa570I_I3.

Cakir, S.G., \& Aydin, G. (2005). Parental attitudes and ego identity status of turkish adolescents. Adolescence, 40 (160), 847-859.

Chan, S.M., Bowes, J., \& Wyver, S. (2009). Parenting style as a context for emotion socialization. Early Education and Development, 20 (4), 63I-656. doi: 10. 1080/1040928080254I973.

Coolican, H. (2014). Research methods and statistics in psychology (6th ed.). Psychology Press, Taylor \& Francis Group, New York.

Cripps, K., \& Zyromski, B. (2009) Adolescents' psychological well-being and perceived parental involvement: implications for parental involvement in middle schools. Research in Middle Level Education, 33 (4), I-13. doi: 10. 1080/19404476.2009.1 I462067.

Dariling, N., \& Steinberg, L. (1993). Parenting style as context: an integrative model. Psychological Bulleting, I I3 (3), 487 - 497. doi: 10.1348/026151004I552765.

Ghassemi, A. E. (2017). Assessing college students' ego-identity status and their use of motivational regulation strategies, International Journal of Mental Health. doi: 10.1080/002074II.2017.1367449.

Ginsburg, G. S., \& Bronstein, P. (1993). Family factors related to children's intrinsic/extrinsic motivational orientation and academic performance. Child Development. 64, I46 I - I 474. 
Grové, L.C., \& Naudé, L. (2016). Identity status and perceived parenting style in adolescents living in central South Africa. Journal of Psychology in Africa, 26(2), 189-193. doi: I0.1080/I4330237.2016.11728II.

Ickes, W., Park, A., \& Johnson, A. (2012). Linking identity status to strength of sense of self: theory and validation. Self and Identity, II(4), 53I-544. doi: 10.1080/I5298868.20II.625646.

Johnson, B. (200I). Toward a new classification of nonexperimental quantitative research. Educational Researcher, 30 (2), 3-I3.

Kailay, E., \& Rus, C. (20/4). Psychometric properties of the 44-item version of ryff's psychological well-being scale. European Journal of Psychological Assessment, 30 (I), 15-2I. doi: 10.1027/1015-5759/a000163.

Knafo-Noam, A., \& Schwartz, S. H. (2004). Identity status and parent-child congruence in adolescence. British Journal of Developmental Psychology, 22, 439-458.

Kroger, J. (2000). Ego identity status research in the new millennium. International Journal of Behavioral Development, 24(2), 145-I48. doi: 10.1080/016502500383250.

Luyckx, K., Schwartz, S. J., Goossens, L., \& Pollock, S. (2008). Employment, sense of coherence, and identity formation: Contextual and psychological processes on the pathway to sense of adulthood. Journal of Adolescent Research, 23, 566-591.

Luyckx, K., Vansteenkiste, M., Goossens, L., \& Duriez, B. (2009). Basic need satisfaction and identity formation: Bridging self-determination theory and process-oriented identity research. Journal of Counseling Psychology, 56, 276-288.

Maccoby, E. E. and Martin, J. A. (1983). Socialization in the context of the family: Parent -child value interaction. In a Mussen, P. H. (eds.) Handbook of child psychology. New York:Wiley.

Marcia, J. E. (1980). Identity in adolescence. In J. Adelson (Ed.), Handbook of Adolescent Psychology. New York: Wiley.

Marcia, J. E. (1994). The empirical study of ego identity. In H. A. Bosma \& L. G. Tobi (Eds.), Identity and Development: An Interdisciplinary Approach. Thousand Oaks, CA: Sage.

Marcia, J. E. (1966). Development and validation of ego identity status. Journal of Personality and Social Psychology, 3 (5), 55I-558. doi: 0. I037/h002328I.

McBride-Chang, C. \& Chang, L. (1998). Adolescent-parent relations in hong kong: parenting styles, emotional autonomy, and school achievement. The Journal of Genetic Psychology, I59 (4), 42I-436. doi: I0.1080/0022I329809596I62. 
Meeus, W., ledema, J., Helsen, M., \& Volleberg, W. (1999). Patterns of adolescent identity development: review of literature and longitudinal analysis. Developmental Review, 19, $4|9-46|$.

Megreya, A. M. \& Ahmed, R. A. (20II) A cross-cultural investigation of identity statuses in Middle Eastern countries. The Journal of North African Studies, I6(I), 49-57. doi: 10.1080/I3629387.2010.49623I.

Milevsky, A., Schlechter, M., Netter, S., \& Keehn, D. (2007). Maternal and paternal parenting styles in adolescents: associations with self-esteem, depression and life-satisfaction. Journal of Childhood and Family Studies, 16, 39-47. doi: 10.1007/s 10826-006-9066-5.

Rivers, J., Mullis, A. K., Fortner, L. A., \& Mullis, R. L. (2012). Relationships between parenting styles and the academic performance of adolescents. Journal of Family Social Work, 15 (3), 202-2 16. doi: 10.1080/I0522I58.20I2.666644.

Ryeng, M.S., Kroger, J., \& Martinussen, M. (2013). Identity status and authoritarianism: a metaanalysis. Identity, 13 (3), 242-252. doi: 10.1080/I5283488.20I3.799434.

Ryff C. D. (1989). Happiness is everything, or is it? Explorations on the meaning of psychological well-being. Journal of Personality and Social Psychology, 57, 1069-108I. doi: 10.1037/002235I4.57.6.1069.

Sandhu, D., Singh,B., Tung,S. \& Kundra, N. (2012). Adolescent identity formation, psychological well-being, and parental attitudes. Pakistan Journal of Psychological Research, 27(I), 89-105.

Schawartz, S. J., Donnelan, B., Ravert, R. D., Luycks, K., \& Zamboanga, B. (2012). Identity development, personality and well-being in adolescence and emerging adulthood. In $\mathrm{A}$ I.B., Weiner, R.M., Lerner, M.A., Easterbrooks, \& Mistry, J. (eds) Handbook of Psychology, Developmental Psychology. Wiley.

Schwartz, S. J., Mullis, Waterman, A.S., \& Dunham, R.M. (2000). Ego identity status, identity style, and personal expressiveness: an empirical investigation of three convergent constructs. Journal of Adolescent Research, 15 (4), 504-52I.

Sestito, L.A. \& Sica, L. S. (20I4). Identity formation of Italian emerging adults living with parents: a narrative study. Journal of Adolescence, 37, I435-I447. doi: 10.1016/j.adolescence.2014.02.013.

Shucksmith, J., Hendry, L. B., \& Glendinning, A. (1995). Models of parenting: implications for adolescent well-being within different types of family context. Journal of Adolescence, 18, 253-270. 
Simons, L. G., \& Conger, R. D. (2007). Linking mother-father differences in parenting to a typology of family parenting styles and adolescent outcomes. Journal of Family Issues, 28 (2), 212-24I. doi: 10.1 177/01925I3X06294593.

Smetana, J. (1995). Parenting styles and conceptions of parental authority during adolescence. Child Development. 66, 299-316.

Smits. I., Soenens, B., Luyckx, K. Duriez, B., Berzonsky, M., \& Goossens, L. (2008). Perceived parenting dimensions and identity styles: exploring the socialization of adolescents' processing of identity-relevant information. Journal of Adolescence, $3 \mathrm{I}$, I5I-I64.

Sorkhabi, N. (2012). Parent socialization effects in different cultures: significance of directive parenting. Psychological Reports, I I0(3), 854-878. doi:10.2466/10.02.17.21.

Spera, C. (2005). A review of the relationship among parenting practices, parenting styles, and adolescent school achievement. Educational Psychology Review, I7(2), 125-I46. doi: 10.1007/s I0648-005-3950-I.

Syed, M. \& Seiffge-Krenke, I. (2012). Personality development from adolescence to emerging adulthood: linking trajectories of ego development to the family context and identity formation. Journal of Personality and Social Psychology, 104(2), 37I-384. doi: 10.1037/a0030070.

Tabachnick, B. G. \& Fidell, L. S. (20I2). Using multivariate statistics (6th ed.). Pearson, Boston. 